\title{
Inhibition of Agrin-Induced Acetylcholine-Receptor Aggregation by Heparin, Heparan Sulfate, and Other Polyanions
}

\author{
Bruce G. Wallace \\ Department of Neurobiology, Stanford University School of Medicine, Stanford, California 94305
}

\begin{abstract}
Heparin and heparan sulfate have been shown to block nerveinduced acetylcholine-receptor (AChR) aggregation at developing neuromuscular junctions. We found that heparin, heparan sulfate, and a wide variety of other polyanions also inhibited agrin-induced $\mathrm{AChR}$ aggregation. The more highly charged the polyanion, the more potent it was as an inhibitor. Inhibition of agrin-induced AChR aggregation was due, at least in part, to the formation of a complex between the polyanion and agrin that was inactive. These findings are consistent with the hypothesis that nerve-induced aggregation of AChRs is mediated by the release of agrin, or a closely related protein, from axon terminals and suggest that a polyanion, such as a sulfated proteoglycan, may be involved in the interaction of agrin with its receptor on the myotube surface.
\end{abstract}

During the formation of the vertebrate skeletal neuromuscular junction, the axon terminal signals the developing myofiber to assemble a postsynaptic apparatus at the site of nerve-muscle contact (Dennis, 1981). This postsynaptic spccialization is characterized by high concentrations of cytoplasmic, membrane, and extracellular-matrix components, including aggregates of acetylcholine receptors (AChRs) in the myofiber's plasma membrane and accumulations of AChE in the synaptic basal lamina (Fertuck and Salpeter, 1974; McMahan et al., 1978). Little is known about the mechanism of formation of the postsynaptic apparatus or the signals that induce it. The most thoroughly studied aspect of postsynaptic differentiation is nerve-induced accumulation of AChRs, which requires $\mathrm{Ca}^{2+}$ (Henderson et al., 1984) and occurs, at least in part, by lateral migration of AChRs in the myotube plasma membrane (Anderson and Cohen, 1977; Ziskind-Conhaim et al., 1984; Kuromi et al., 1985; but see Role et al., 1985). In addition, Hirano and Kidokoro (1989) have reported that heparin and heparan sulfate block nerve-induced AChR aggregation in Xenopus nerve-muscle cocultures. They speculated that heparin and heparan sulfate did not interfere directly with the mechanism by which muscle cells formed ag-

\footnotetext{
Received Mar. 30, 1990; revised June 25, 1990; accepted July 5, 1990.

I thank Drs. S. Kroger and M. Werle for their constructive criticisms of the manuscript, Yiran Wang and Robert Marshall for their technical assistance, Cecele Thomas for her excellent secretarial support, and Dr. U. J. McMahan for his support and advice. These studies were funded by NIH Grant NS14506, the Muscular Dystrophy Association of America, the Isabelle Niemela Fund, and a gift from Mr. Keith Linden.

Correspondence should be addressed to Bruce G. Wallace, Department of Physiology, University of Colorado Health Sciences Center, Campus Box C240, 4200 East Ninth Avenue, Denver, CO 80262.

Copyright (C) 1990 Society for Neuroscience $0270-6474 / 90 / 113576-07 \$ 03.00 / 0$
}

gregates of AChRs, but rather disrupted the signaling between the axon terminal and the muscle cell.

One candidate for such a signal is agrin, a protein purified from the electric organ of Torpedo californica (Godfrey et al., 1984; Nitkin et al., 1987). Agrin, or a closely related protein, is found in the cell bodies of spinal motor neurons, both in the embryo and in the adult (Magill-Solc and McMahan, 1988, 1989), is transported down motor axons (Magill-Solc and McMahan, 1989), and, when added to myotubes in culture, induces the formation of specializations on their surface at which several components of the postsynaptic apparatus are aggregated, including AChRs and AChE (Godfrey et al., 1984; Wallace et al., 1985; Wallace, 1986, 1989). Agrin-induced aggregation of $\mathrm{AChRs}$ requires $\mathrm{Ca}^{2+}$ and occurs by lateral migration (Godfrey et al., 1984; Wallace, 1988). These and other findings have led to the hypothesis that agrin is released from axon terminals at developing neuromuscular junctions to induce the differentiation of the postsynaptic apparatus and becomes incorporated into the synaptic basal lamina, where it serves to maintain those spccializations in the adult and direct their formation during regeneration (Nitkin et al., 1987; Reist et al., 1987; Wallace, 1988; McMahan and Wallace, 1989).

To gain insight into how heparin and heparan sulfate might prevent accumulation of AChRs, we studied the effects of these and other polyanions on agrin-induced AChR aggregation. We found that heparin and heparan sulfate inhibited agrin-induced AChR aggregation. We also found that a wide variety of polyanions mimicked the effects of heparin and heparan sulfate, and that polyanion inhibition of agrin-induced AChR aggregation was due, at least in part, to the formation of a complex between the polyanion and agrin that was inactive.

\section{Materials and Methods}

Chick myotube cultures. Myotube cultures were prepared from hindlimb muscles of 11-12-d-old White Leghorn chick embryos by the method of Fischbach (1972), with minor modifications (Wallace, 1989). Experiments were routinely made on 5-6-d-old myotube cultures that were transferred to defined medium [a 1:1 mixture of Dulbecco's Modified Eagle's Medium and Ham's nutrient mixture F-12 (DME/F12) (Sigma Chemical Co., St. Louis, MO) supplemented with $0.8 \mathrm{~mm} \mathrm{CaCl}, 1 \mathrm{mg} /$ $\mathrm{ml}$ BSA (RIA grade, Sigma), $100 \mathrm{U} / \mathrm{ml}$ penicillin, and $0.1 \mathrm{mg} / \mathrm{ml}$ streptomycin] on the day of the experiment.

Agrin. Most experiments were made with partially purified preparations of agrin (Cibacron pool) prepared from the electric organ of Torpedo californica as previously described (Nitkin et al., 1987). For experiments on binding to derivatized Sephadex and Sepharose beads, agrin was purified on a monoclonal-antibody 6D4 immunoaffinity resin as previously described (Nitkin et al., 1987), except that the final eluate was immediately neutralized with $1 / 10$ vol $1 \mathrm{M}$ Tris- $\mathrm{Cl}(\mathrm{pH}, 7.6)$ to preserve activity.

Quantification of $A C h R$ aggregation. AChR aggregates were visualized and counted as previously described (Wallace, 1986, 1988). 

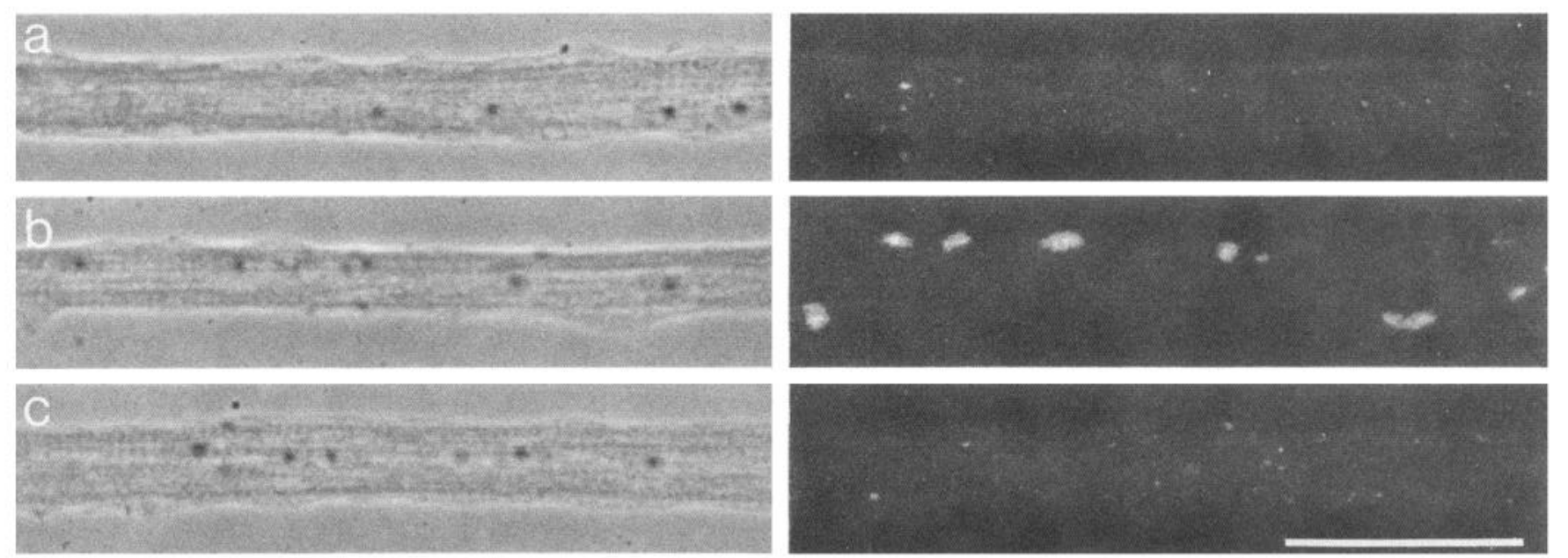

Figure 1. Heparin inhibits agrin-induced AChR aggregation. Phase-contrast (left) and fluorescence (right) micrographs of segments of myotubes from cultures incubated $15 \mathrm{hr}$ in normal medium $(a)$, agrin $(b)$, or agrin with $0.05 \mathrm{mg} / \mathrm{ml}$ heparin $(c)$ and labeled with rhodamine $\alpha$-bungarotoxin to reveal the distribution of AChRs. Heparin caused no discernible change in the appearance of the myotubes or spontaneously occurring AChR aggregates, but inhibited agrin-induced AChR aggregation. Scale bar, $50 \mu \mathrm{m}$.

Reagents. Heparin (Grade I, sodium salt), heparan sulfate (sodium salt from bovine kidney), chondroitin sulfate (Type A, sodium salt from bovine trachea), hyaluronic acid (sodium salt from bovine trachea), poly-L-aspartic acid (sodium salt; MW, 5000-15,000), dextran sulfate (sodium salt; average MW, 8000), fucoidin, D-glucosamine 2,3-disulfate, D-glucosamine 2,6-disulfate, D-glucosamine 2-sulfate, CM-Sephadex (C-50, 100-200 mesh), SP-Sephadex (C-50, 40-120 $\mu \mathrm{m})$, and heparin-agarose (Type II) were obtained from Sigma. Dextran (T-10; MW, 10,000), Sephadex (G-50, 50-150 $\mu \mathrm{m}$ ), and DEAE-Sephadex (A$50,40-120 \mu \mathrm{m}$ ) were from Pharmacia Fine Chemicals (Piscataway, NJ). Tetramethylrhodamine- $\alpha$-bungarotoxin was from Molecular Probes (Eugene, OR).

\section{Results}

\section{Heparin inhibits agrin-induced AChR aggregation}

Hirano and Kidokoro (1989) have shown that addition of heparin or heparan sulfate to nerve-muscle cocultures inhibits the accumulation of AChRs at sites of nerve-muscle contact. To determine the effect of heparin on agrin-induced $\mathrm{AChR}$ aggregation, heparin was added to chick-myotube cultures together with agrin, the cultures were incubated for $15 \mathrm{hr}$, then the distribution of AChRs was visualized using rhodamine $\alpha$-bungarotoxin. As illustrated in Figures 1 and 2, $0.05 \mathrm{mg} / \mathrm{ml}$ heparin prevented agrin-induced $\mathrm{AChR}$ aggregation. Myotubes exposed to heparin were indistinguishable from controls by phase-contrast microscopy, and heparin had no discernible effect on the number or size of spontaneously occurring $\mathrm{AChR}$ aggregates. This suggests that inhibition of AChR aggregation by heparin was not the result of some general cytotoxic effect.

\section{Effects of heparin are reversible}

To determine the extent to which the effects of heparin were reversible, myotubes were incubated with medium containing $0.05 \mathrm{mg} / \mathrm{ml}$ heparin for $15 \mathrm{hr}$, rinsed twice, then treated with agrin for $7 \mathrm{hr}$ in normal medium. Pretreatment with heparin had no discernible effect on the subsequent response of myotubes to agrin (Fig. 2), providing further evidence that inhibition of agrin-induced AChR aggregation by heparin is not due to cytotoxicity. Likewise, incubating agrin in $0.4 \mathrm{mg} / \mathrm{ml}$ heparin for $2 \mathrm{hr}$ before adding it to myotube cultures had no effect on agrin's AChR-aggregating activity (Fig. 2), indicating that heparin did not irreversibly inactivate or remove agrin from so-

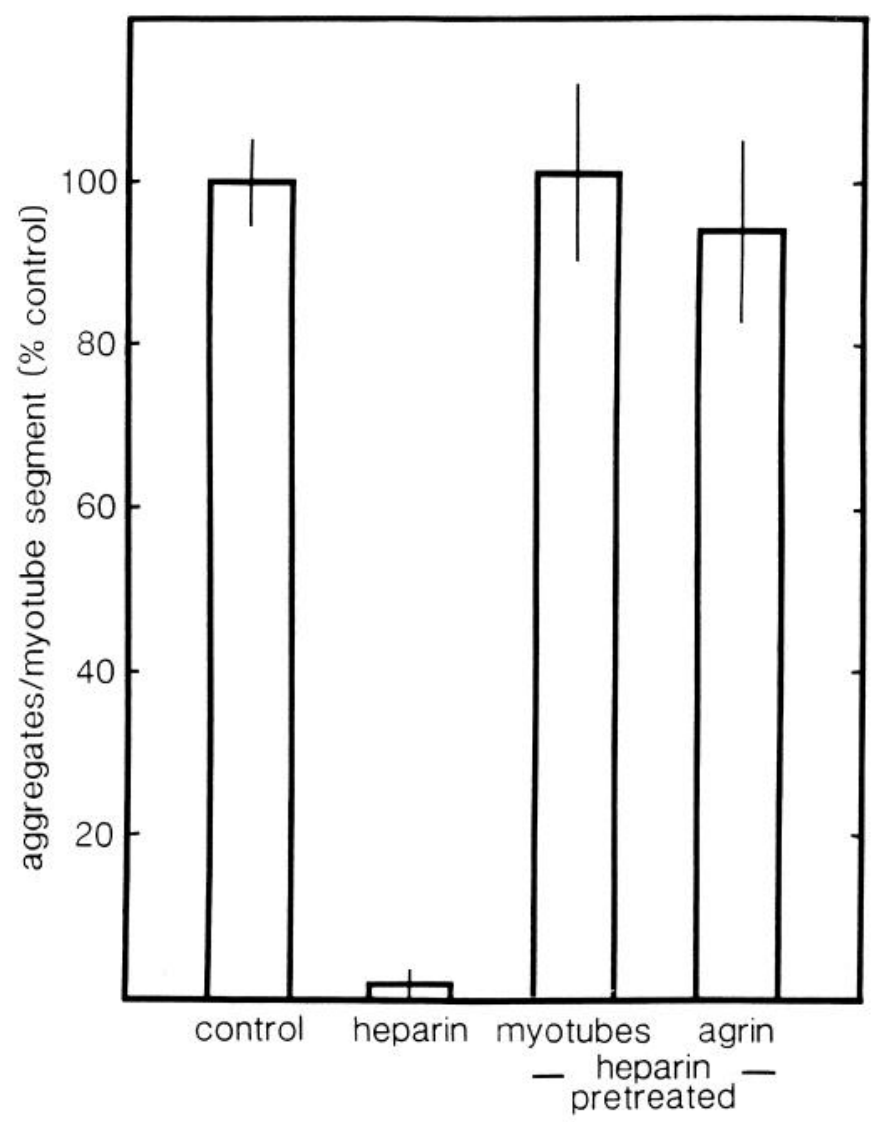

Figure 2. Heparin must be present together with agrin to inhibit AChR aggregation. Myotube cultures were treated for $15 \mathrm{hr}$ with agrin (control) or agrin with $0.05 \mathrm{mg} / \mathrm{ml}$ heparin (heparin), and the number of AChR aggregates was determined. When added together with agrin, heparin completely blocked agrin-induced AChR aggregation. There was no change in the number of aggregates of AChRs induced by 7-hr treatment with agrin when either myotubes or agrin were pretreated with heparin (myotubes: incubated $15 \mathrm{hr}$ in medium containing $0.05 \mathrm{mg} / \mathrm{ml}$ heparin, rinsed twice, then treated with agrin in normal medium; agrin: $9 \mathrm{U}$ Cibacron pool were incubated $2 \mathrm{hr}$ in $45 \mu \mathrm{l}$ medium containing $0.4 \mathrm{mg} /$ $\mathrm{ml}$ heparin, then 15- $\mu$ l aliquots were added to myotube cultures containing $1.5 \mathrm{ml}$ medium, giving a final heparin concentration of 0.004 $\mathrm{mg} / \mathrm{ml})$. Data, expressed as percent of control, are mean $\pm \operatorname{SEM}(N=$ $3)$. 


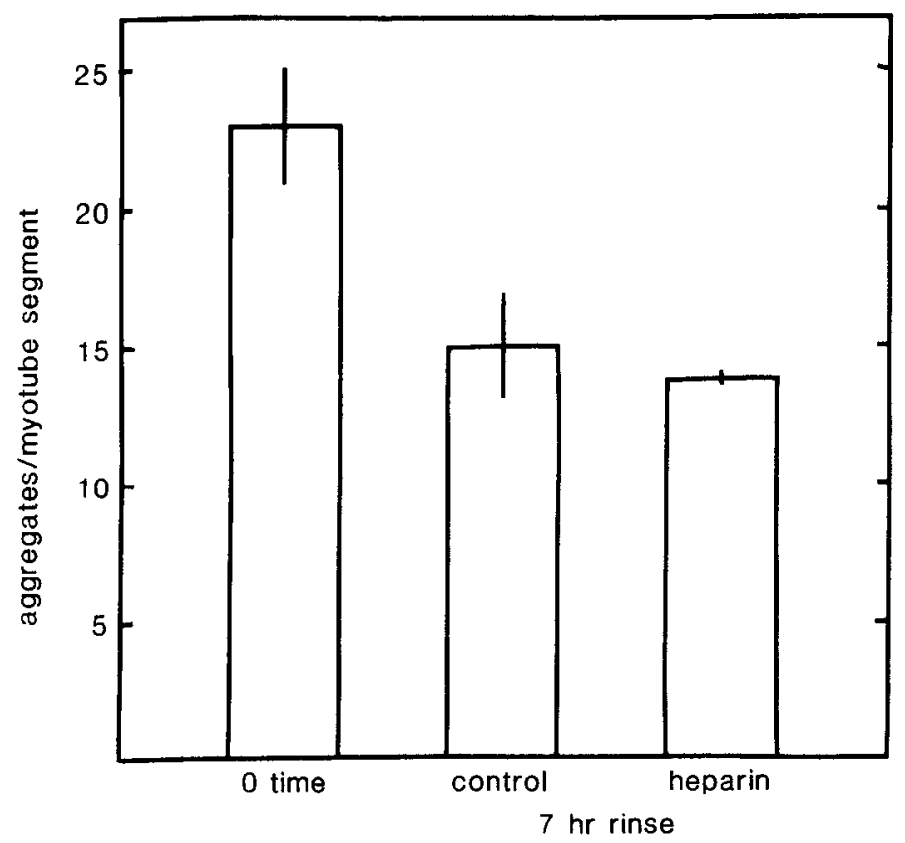

Figure 3. Heparin does not affect stability of AChR aggregates. Cultures were treated overnight with agrin to induce the formation of $\mathrm{AChR}$ aggregates, rinsed to remove agrin, then fixed and labeled with rhodamine $\alpha$-bungarotoxin immediately ( 0 time) or after $7 \mathrm{hr}$ incubation in normal medium (control) or medium supplemented with $0.05 \mathrm{mg} / \mathrm{ml}$ heparin (heparin), and the number of AChR aggregates was counted. Heparin did not affect the rate at which AChR aggregates disappear after agrin is removed. Data is expressed as mean \pm SEM $(N=3)$.

lution. Therefore, heparin must be present together with agrin in the myotube cultures to prevent AChR aggregation.

\section{Heparin has no effect on the maintenance of agrin-induced AChR aggregates}

Heparin might decrease the number of $\mathrm{AChR}$ aggregates in agrintreated cultures by preventing the formation of $\mathrm{AChR}$ aggregates and/or by destabilizing aggregates so that they disperse as rapidly as they are formed. To examine directly the effects of heparin on aggregate stability, myotubes were pretreated with agrin overnight to induce aggregate formation, then agrin was removed, and the cultures were incubated for an additional $7 \mathrm{hr}$ in normal medium or medium supplemented with $0.05 \mathrm{mg} / \mathrm{ml}$ heparin. When myotubes arc cultured in normal medium, agrininduced AChR aggregates disappear slowly after agrin is removed (Wallace, 1988). As illustrated in Figure 3, heparin did not affect the disappearance of agrin-induced $A C h R$ aggregates. Therefore, heparin must reduce the number of $A C h R$ aggregates in agrin-treated cultures by inhibiting aggregate formation.

\section{Inhibition of agrin-induced AChR aggregation by other polyanions}

We next sought to determine the properties of heparin that were responsible for its inhibitory activity (Fig. 4). We first examined the effects of other glycosaminoglycans. Heparan sulfate inhibited agrin-induced AChR aggregation, but was considerably less potent than heparin. Chondroitin sulfate also caused some inhibition of agrin-induced AChR aggregation, but only at much higher concentrations. Hyaluronic acid had no detectable effect at concentrations as high as $0.5 \mathrm{mg} / \mathrm{ml}$. Therefore, the potency of glycosaminoglycans as inhibitors increased in parallel with their charge density (hyaluronic acid $<$ chondroitin sulfate $<$ heparan sulfate $<$ heparin).

To test whether the repeating disaccharide structure of glycosaminoglycans was important for inhibition, a variety of other carbohydrate polymers were tested. Dextran, an uncharged polymer of glucose, was ineffective as an inhibitor, while dextran sulfate, which is more heavily sulfated than heparin, was a more potent inhibitor than heparin. Of the compounds investigated, the most potent inhibitor was fucoidin, a very heavily sulfated polymer of fucose. On the other hand, monomeric sulfated sugars $(0.5 \mathrm{mg} / \mathrm{ml})$ had little effect on agrin-induced AChR aggregation [D-glucosamine 2-sulfate, $94 \pm 9 \%$ of control (mean \pm SEM, $N=4$ ); D-glucosamine 2,3-disulfatc, $90 \pm 6 \%$; D-glucosamine 2,6-disulfate, $91 \pm 5 \%$ ], indicating that polymeric structure is important for inhibition.

Polyaspartic acid, a polymer of an amino acid rather than of sugar residues, was about as effective an inhibitor as chondroitin sulfate. Polyaspartic acid has about the same density of charged residues as chondroitin sulfate, but they are all carboxyl groups, indicating that neither a carbohydrate backbone nor sulfation is required for inhibition. Therefore, polyanions other than glycosaminoglycans inhibited agrin-induced AChR aggregation; the potency of a polyanion as an inhibitor appeared to be determined by the overall charge density of the molecule rather than the charged group itself (sulfate or carboxyl) or the nature of the polymeric backbone (fucose, glucose, glycosaminoglycan, or amino acid).

\section{Mechanism of inhibition by polyanions}

To characterize further how polyanions inhibited agrin's effects, we examined the dose dependence of agrin-induced AChR aggregation in the presence and absence of one of the most potent polyanionic inhibitors, dextran sulfate. As is illustrated in Figure 5 , the effect of dextran sulfate was to shift the dose-response curve to higher agrin concentrations. This pattern would result if polyanions such as dextran sulfate prevented agrin-induced AChR aggregation by inhibiting competitively the interaction of agrin with a receptor on the myotube surface or if agrin formed a complex with the polyanion that was inactive.

To test the possibility that agrin formed inactive complexes with polyanions, we examined the binding of agrin to a variety of derivatized Sephadex and Sepharose beads (Fig. 6). Agrin and beads were mixed together in culture medium, then the beads were removed by centrifugation and the supernatant assayed for $\Lambda \mathrm{ChR}$-aggregating activity. Beads bearing negatively charged residues removed approximately $60 \%$ of the agrin from the supernatant, while uncharged beads or beads bearing positively charged residues bound little or no agrin. Therefore, agrin does bind to polyanions, and this could account, at least in part, for their inhibitory activity. As illustrated in Figure 7, the binding of agrin to heparin-conjugated beads was reduced by approximately $30 \%$ in the absence of $\mathrm{Ca}^{2+}$, which might contribute to the $\mathrm{Ca}^{2+}$ dependence of agrin-induced $\mathrm{AChR}$ aggregation (see Discussion).

\section{Discussion}

Several lines of evidence suggest that, at developing neuromuscular junctions, agrin is released from axon terminals and combines with a receptor on the myotube surface to induce the formation of the postsynaptic apparatus (see McMahan and Wallace, 1989). The results reported here support this hypothesis by demonstrating that agrin-induced AChR aggregation is 


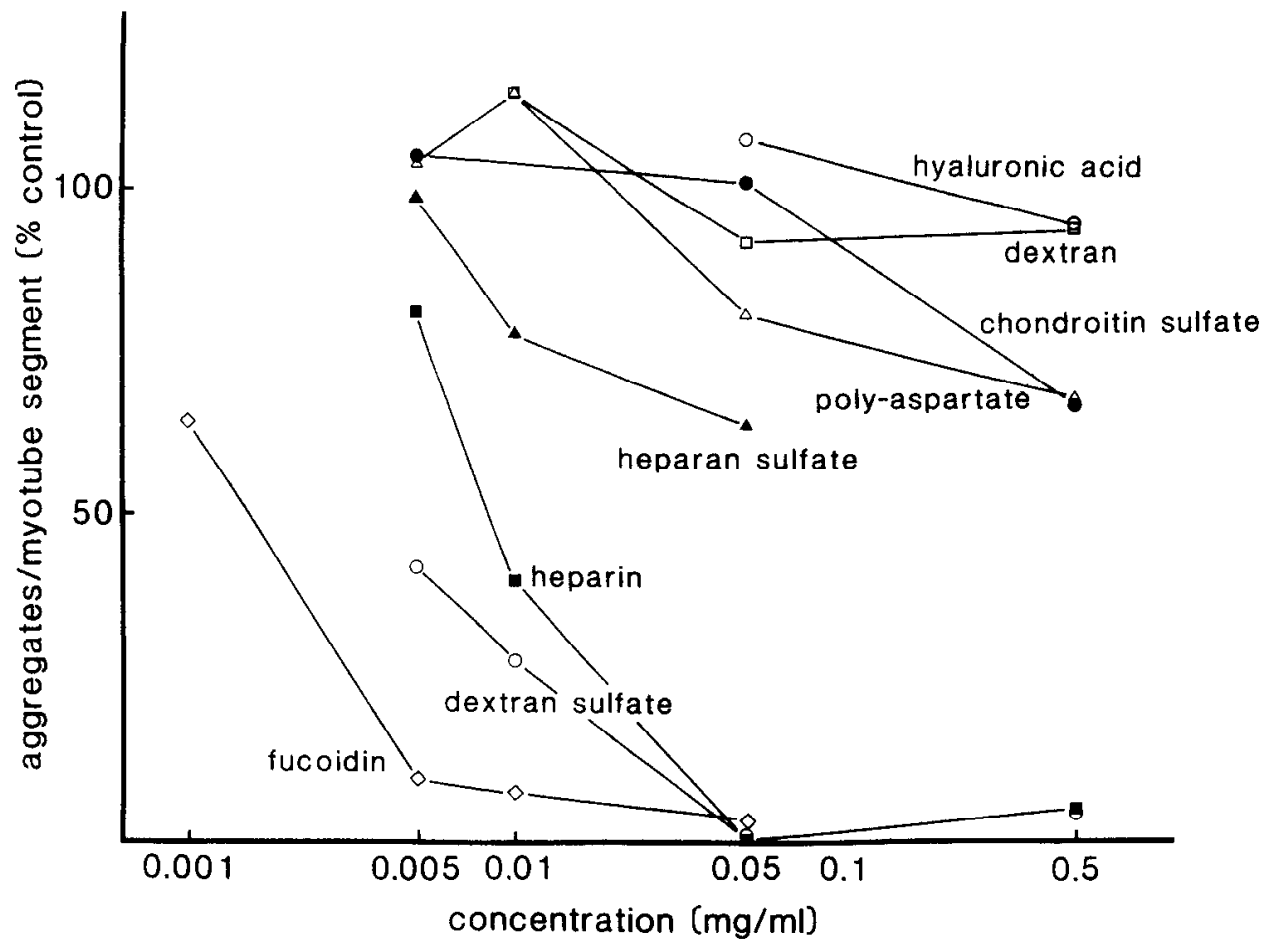

Figure 4. Effects of neutral and negatively charged polymers on agrin-induced AChR aggregation. Myotube cultures were treated with agrin overnight in normal medium or medium supplemented with the indicated concentration of various polymers. AChRs were labeled with rhodaminc $\alpha$-bungarotoxin, and the number of AChR aggregates was determined. Each data point is the mean of 3-18 determinations. Neutral (dextran) or lightly charged (hyaluronic acid) polymers had little or no effect on agrin-induced AChR aggregation; moderately (chondroitin sulfate) to intensely (fucoidin) charged polyanions were inhibitory. blocked by heparin and heparan sulfate, 2 polyanions that have been shown to prevent nerve-induced accumulation of AChRs at developing neuromuscular junctions (Hirano and Kidokoro, 1989).

\section{Mechanism of inhibition of agrin-induced AChR aggregation}

Polyanions such as heparin have been shown to bind to a wide variety of glycoproteins, including members of the immunoglobulin gene superfamily (NCAM, CD2, CD4; Lederman et al., 1989), anticoagulation factors (antithrombin III, heparan cofactor II, protein C inhibitor; Ofosu et al., 1989; Pratt et al., 1989), extracellular matrix components (laminin: Skubitz et al., 1988; fibronectin: Rogers et al., 1985; vitronectin: Suzuki et al., 1985), and growth factors (aFGF, bFGF; Barzu et al., 1989; Burgess and Maciag, 1989). Binding of polyanions to some proteins, such as laminin, appears to be selective for heparinlike glycosaminoglycan side chains, and this specificity may play a role in establishing the structure of the basal lamina and regulating the interaction of cells with it (Skubitz et al., 1988). In many cases, however, binding of polyanions is much less selective, and polyanions that are clearly nonphysiological, such as sulfated dextran, bind with high affinity. For example, a variety of polyanions in addition to heparin inhibit competitively neural cell adhesion to an NCAM substrate (Cole and Glaser, 1986) and the interaction of CD4 with the gp 120 coat protein of HIV (Lederman et al., 1989). These observations have led to the speculation that a variety of extracellular and cell-surface ligandreceptor interactions might be strengthened by the interaction of a polyanion binding site on the ligand with sulfated carbohydrate residues on the receptor (Lederman et al., 1989). Our finding that polyanions bind to agrin and inhibit agrin-induced AChR aggregation is consistent with the hypothesis that a similar interaction is important for agrin's binding to and activation of its receptor.

The binding of agrin to such a polyanionic site on its receptor might be expected to depend on $\mathrm{Ca}^{2+}$ in a manner similar to the binding of agrin to heparin beads, which could account, at least in part, for the requirement for $\mathrm{Ca}^{2+}$ in agrin-induced $\mathrm{AChR}$ aggregation (Wallace, 1988).

The heparin-agarose beads used in the binding experiments contain $0.75 \mathrm{mg}$ heparin per $\mathrm{ml}$ of packed gcl. Eight $\mu \mathrm{l}$ of beads

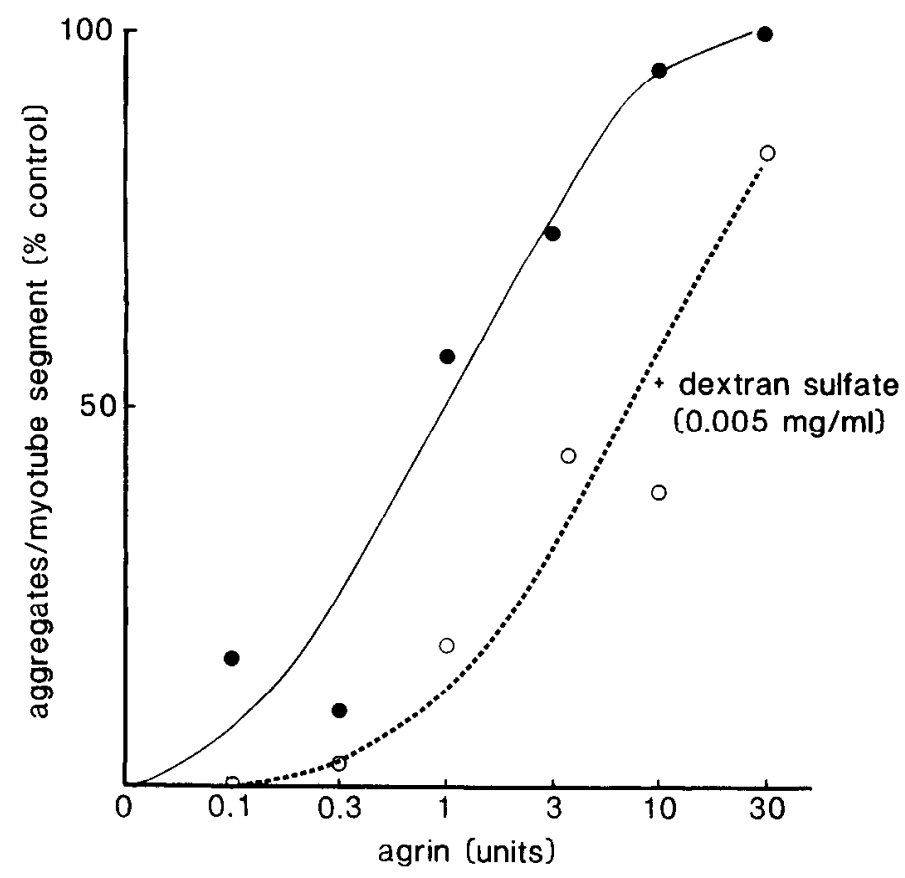

Figure 5. Polyanions shift the dose-response curve for agrin-induced AChR aggregation to higher concentrations. Myotube cultures were incubated overnight with the indicated concentration of agrin in normal medium or medium supplemented with $0.005 \mathrm{mg} / \mathrm{ml}$ dextran sulfate. AChRs were labeled with rhodamine $\alpha$-bungarotoxin, and the number of AChR aggregates was counted. Each data point is the mean of triplicate determinations; curves were fit by eye. 


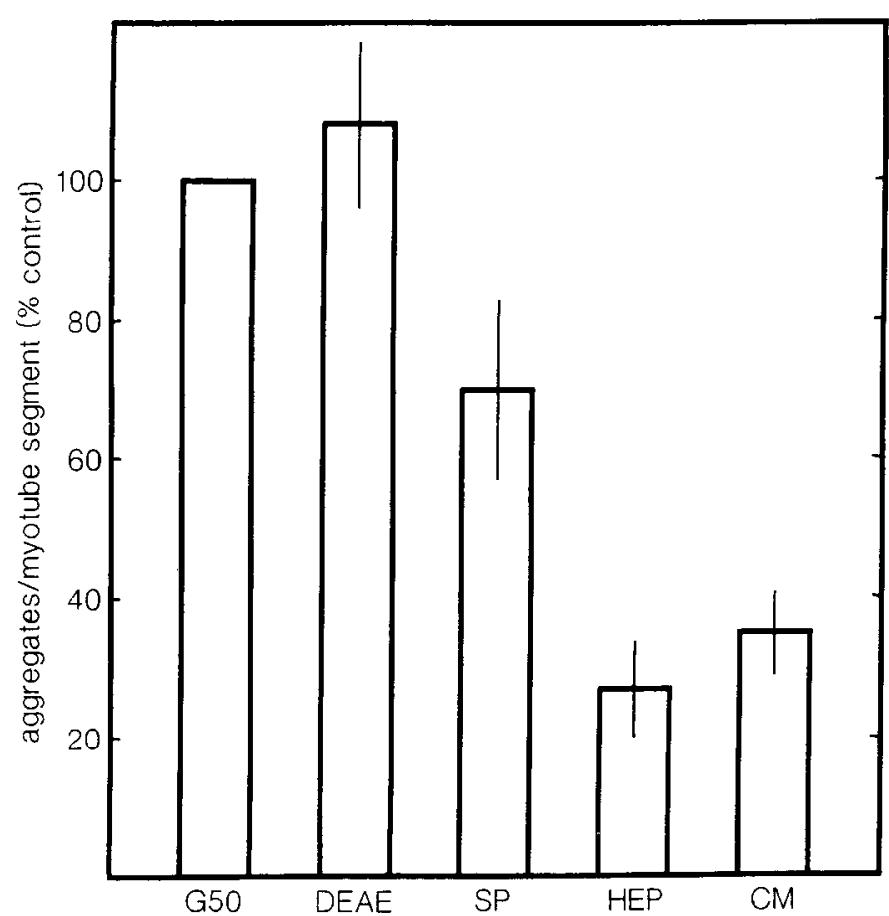

Figure 6. Agrin binds to negatively charged beads. Immunoaffinitypurified agrin (equivalent to $3 \mathrm{U} /$ culture) was incubated with $8 \mu \mathrm{l}$ beads in $40 \mu \mathrm{l}$ culture medium for $1.5 \mathrm{hr}$, the beads were removed by centrifugation, and aliquots of the resulting supernatant were added to myotube cultures overnight to assay for residual AChR-aggregating activity. Data, expressed as a percentage of the activity remaining after treatment with Sephadex G-50, are mean \pm SEM $(N=3)$. [In control experiments, $87 \pm 7 \%$ (mean $\pm \mathrm{SEM}, N=3$ ) of the agrin remained in the supernatant after incubation with Sephadex $\mathrm{G}-50$ beads compared to no beads at all.] $G 50$, Sephadex G-50 $(50-150 \mu \mathrm{m})$, uncharged; $D E A E$, DEAE-Sephadex (A-50, 40-120 $\mu \mathrm{m}$ ), positively charged; $S P$, SP-Sephadex $(\mathrm{C}-50,40-120 \mu \mathrm{m})$, negatively charged $\left(\mathrm{SO}_{4}{ }^{-2}\right) ; H E P$, heparinagarose ( $4 \%$ cross-linked beaded agarose), negatively charged; $C M, C M-$ Sephadex (C-50, 100-200 mesh), negatively charged (COO ${ }^{-}$).

were incubated with $12 \mathrm{U}$ agrin in a total vol of $40 \mu \mathrm{l}$. If we assume that all the bound heparin is accessible, this corresponds to an average concentration of $0.15 \mathrm{mg} / \mathrm{ml}$ heparin. Under these conditions, the agrin concentration in the supernatant was reduced by $80 \%$, to $2.4 \mathrm{U}$. On the other hand, when added together with agrin to myotube cultures, $0.15 \mathrm{mg} / \mathrm{ml}$ heparin inhibited AChR aggregation $100 \%$; only $0.02 \mathrm{mg} / \mathrm{ml}$ was required to reduce the effective agrin concentration by $80 \%$. It is difficult to determine whether or not it is appropriate to make such a quantitative comparison between the binding of agrin to heparincoated beads and the inhibition of agrin-induced AChR aggregation by heparin in solution. Nevertheless, the apparent discrepancy raises the possibility that polyanions might inhibit agrin-induced AChR aggregation by some additional mechanism.

\section{Dose-dependent inhibition of nerve- and agrin-induced AChR aggregation by polyanions}

Hirano and Kidokoro (1989) showed that heparin and heparan sulfate inhibited nerve-induced AChR aggregation in a dosedependent manner: $0.5 \mathrm{mg} / \mathrm{ml}$ reduced AChR accumulation approximately $50 \%$. Likewise, we found that heparin and heparan sulfate, as well as other polyanions, also inhibited agrininduced $\mathrm{AChR}$ aggregation in a dose-dependent manner. However, under our standard assay conditions, heparin and heparan

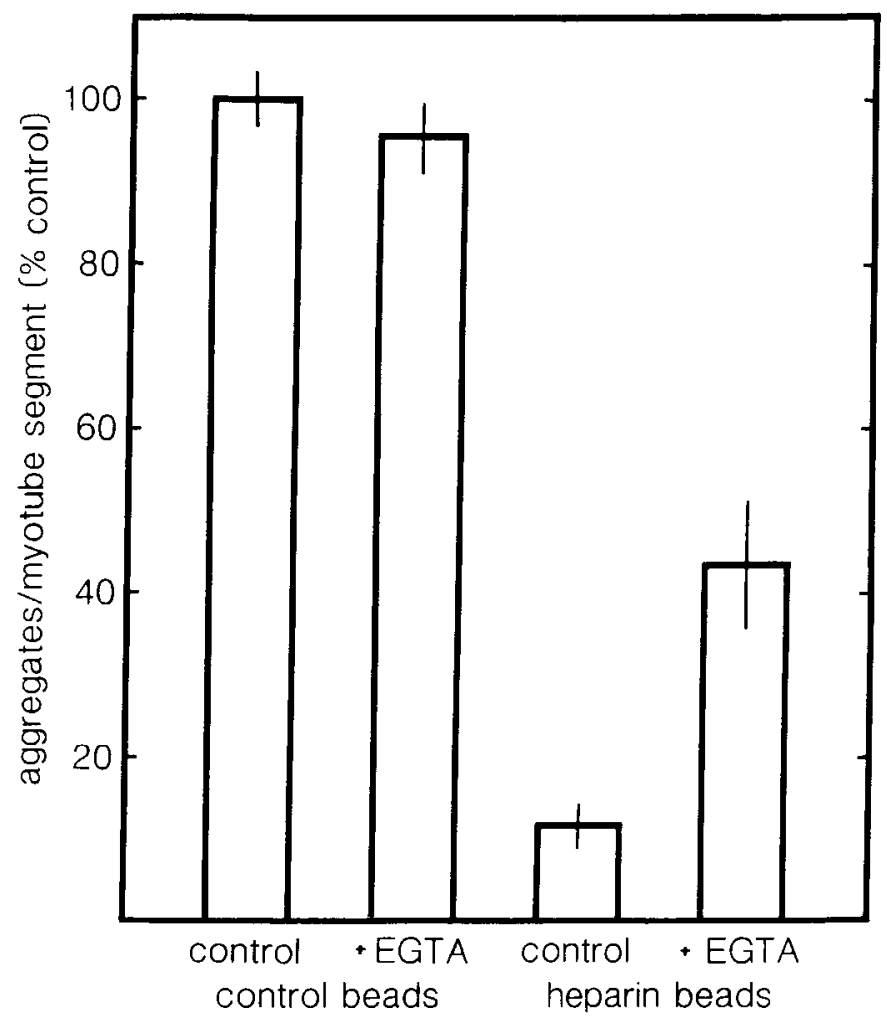

Figure 7. Binding of agrin to heparin beads is reduced by removing $\mathrm{Ca}^{2+}$. Immunoaffinity-purified agrin (equivalent to $2 \mathrm{U} /$ culture) was incubated with $8 \mu \mathrm{l}$ beads in $40 \mu \mathrm{l}$ culture medium $\pm 3 \mathrm{~mm}$ EGTA for $2 \mathrm{hr}$, the beads were removed by centrifugation, and aliquots of the supernatant were added to myotube cultures and assayed for AChRaggregating activity. Data, expressed as a percentage of the activity remaining after incubation with control beads, are mean $\pm \operatorname{SEM}(N=$ 6). Control beads, $4 \%$ cross-linked agarose conjugated to normal mouse serum; heparin beads, $4 \%$ cross-linked agarose conjugated to heparin. Heparin beads removed approximately $90 \%$ of the agrin in normal medium (from 2 to $0.2 \mathrm{U}$ ) and $60 \%$ of the agrin in $\mathrm{Ca}^{2+}$-free medium (from 2 to $0.8 \mathrm{U}$ ).

sulfate were much more potent: $0.05 \mathrm{mg} / \mathrm{ml}$ heparin or heparan sulfate inhibited agrin-induced AChR aggregation by 100 and $35 \%$, respectively. This difference might arise from the different species used in the 2 studies; Hirano and Kidokoro (1989) studied nerve-induced AChR aggregation in Xenopus nerve-muscle cocultures; we assayed the effects of agrin isolated from the Torpedo electric organ on cultured chick myotubes. On the other hand, our observation that polyanions shift the dose-response curve for agrin to higher concentrations could account for this discrepancy; if the effective concentration of agrin (or an agrinlike molecule) beneath an axon terminal is higher than the justmaximal dose used in our standard assay, as might be expected if it were being released into a narrow synaptic cleft, then higher concentrations of heparin or heparan sulfate would be required to antagonize its effects. Moreover, nerve terminals might bind or degrade heparin and heparan sulfate added to nerve-muscle cocultures, lowering the concentration in the synaptic cleft.

\section{Role of sulfated proteoglycans in synapse formation}

Several lines of evidence suggest that sulfated proteoglycans are important in the formation and/or maintenance of the postsynaptic apparatus at the neuromuscular junction, but what role(s) they play is not clear. For example, Anderson (1986) has shown that one of the first events in the formation of the neuromuscular 
junction is the nerve-induced removal of a muscle-derived heparan sulfate proteoglycan that coats the myotube surface. Subsequently, heparin sulfate proteoglycans accumulate together with acetylcholine receptors at the developing neuromuscular junction and remain concentrated there in the adult (Anderson and Fambrough, 1983; Anderson et al., 1984; Anderson, 1986). On the other hand, Gordon and Hall (1989a) have isolated a muscle-cell line that is deficient in sulfated proteoglycan synthesis and shown that agrin does not induce aggregates of AChRs on such cells, as it does on their normal counterparts (Gordon and Hall, 1989b). However, neurons can induce neurite-associated AChR aggregates on the deficient cells (Lupa et al., 1989).

Our hypothesis that the binding of agrin to its receptor on the myotube surface is strengthened by the interaction of a polyanion binding site on agrin with a sulfated proteoglycan on its receptor provides a framework for interpreting these results. Removal of heparan sulfate proteoglycans by axons as they approach the myotube surface might prevent agrin being bound to inappropriate sites during the early stages of synaptogenesis. Accumulation of heparan sulfate proteoglycan after nerve-muscle contact is established could act as a buffer to aid in maintaining a high concentration of agrin in the synaptic basal lamina. The agrin receptor might lack its sulfated proteoglycan moeity in proteoglycan-deficient mutant myotubes, thus reducing the affinity of the receptor for agrin. This could account for the failure of agrin to induce AChR aggregation. Nerve-induced AChR aggregation might persist, however, owing to a higher concentration of agrin beneath axon terminals and/or to additional molecules (such as sulfated proteoglycans) supplied by the axon terminal. Indeed, vesicles in cholinergic axon terminals contain a chondroitin sulfate proteoglycan that becomes exposed on the presynaptic terminal during transmitter release (Carlson et al., 1986; Carlson and Wight, 1987), and PC-12 pheochromocytoma cells, sensory neurons, and CNS neurons have been shown to express on their surface and to secrete heparan sulfate proteoglycans (Matthew et al., 1985; Dow et al., 1988). Accordingly, increasing the concentration of agrin or adding exogenous polyanions might restore the response to agrin in proteoglycan-deficient myotubes.

\section{References}

Anderson MJ (1986) Nerve-induced remodeling of muscle basal lamina during synaptogenesis. J Cell Biol 102:863-877.

Anderson MJ, Cohen MW (1977) Nerve-induced and spontaneous redistribution of acetylcholine receptors on cultured muscle cells. J Physiol (Lond) 268:757-773.

Anderson MJ, Fambrough DM (1983) Aggregates of acetylcholine receptors are associated with plaques of a basal lamina heparan sulphate proteoglycan on the surface of skeletal muscle fibers. J Cell Biol 97:1396-1411.

Anderson MJ, Klier FG, Tanguay KE (1984) Acetylcholine receptor aggregation parallels the deposition of a basal lamina proteoglycan during development of the neuromuscular junction. J Cell Biol 99: 1769-1784.

Barzu T, Lormeau J-C, Petitou M, Michelson S, Choay J (1989) Heparin-derived oligosaccharides: affinity for acidic fibroblast growth factor and effect on its growth-promoting activity for human endothelial cells. J Cell Physiol 140:538-548.

Burgess WH, Maciag T (1989) The heparin-binding (fibroblast) growth factor family of proteins. Annu Rev Biochem 58:575-606.

Carlson SS, Wight TW (1987) Nerve terminal anchorage protein 1 (TAP-1) is a chondroitin sulphate proteoglycan: biochemical and electronmicroscopic characterization. J Cell Biol 105:3075-3086.

Carlson SS, Caroni P, Kelly RB (1986) A nerve terminal anchorage protein from electric organ. J Cell Biol 103:509-520.

Cole GJ, Glaser L (1986) A heparin-binding domain from NCAM is involved in neural cell-substratum adhesion. J Cell Biol 102:403412.

Dennis MJ (1981) Development of the neuromuscular junction: inductive interactions between cells. Annu Rev Neurosci 4:43-68.

Dow KE, Mirski SEL, Roder JC, Riopelle RJ (1988) Neuronal proteoglycans: biosynthesis and functional interaction with neurons in vitro. J Neurosci 8:3278-3289.

Fertuck HC, Salpeter MM (1974) Localization of acetylcholine receptor by ${ }^{125}$ I-labeled $\alpha$-bungarotoxin binding at mouse motor endplates. Proc Nall Acad Sci USA 71:1376-1378.

Fischbach GD (1972) Synapse formation between dissociated nerve and muscle cells in low density cultures. Dev Biol 28:407-429.

Godfrey EW, Nitkin RM, Wallace BG, Rubin LL, McMahan UJ (1984) Components of Torpedo electric organ and muscle that cause aggregation of acetylcholine receptors on cultured muscle cells. J Cell Biol 99:615-627.

Gordon H, Hall ZW (1989a) Glycosaminoglycan variants in the C2 muscle cell line. Dev Biol 135:1-11.

Gordon H, Hall ZW (1989b) Agrin does not induce AChR clusters in a variant muscle cell. Soc Neurosci Abstr 15:1352.

Henderson LP, Smith MA, Spitzer NC (1984) The absence of calcium blocks impulse-evoked release of acetylcholine but not de novo formation of functional neuromuscular synaptic contacts in culture. J Neurosci 4:3140-3150.

Hirano Y, Kidokoro Y (1989) Heparin and heparan sulfate partially inhibit induction of acetylcholine receptor accumulation by nerve in Xenopus culture. J Neurosci 9:1555-1561.

Kuromi H, Brass B, Kidokoro Y (1985) Formation of acetylcholine receptor clusters at neuromuscular junction in Xenopus cultures. Dev Biol 109:165-176.

Lederman S, Gulick R, Chess L (1989) Dextran sulfate and heparin interact with CD4 molecules to inhibit the binding of coat protein (gp120) of HIV. J Immunol 143:1 149-1154.

Lupa MT, Gordon H, Hall ZW (1989) Interactions of neurons with normal and variant $\mathrm{C} 2$ muscle cells in culture. Soc Neurosci Abstr $15: 1352$.

McMahan UJ, Wallace BG (1989) Molecules in basal lamina that direct formation of synaptic specializations at neuromuscular junctions. Dev Neurosci 11:227-247.

McMahan UJ, Sanes JR, Marshall LM (1978) Cholinesterase is associated with the basal lamina at the neuromuscular junction. Nature 271:172-174.

Magill-Solc C, McMahan UJ (1988) Motor neurons contain agrin-like molecules. J Cell Biol 107:1825-1833.

Magill-Solc C, McMahan UJ (1989) Agrin-like molecules are transported in an anterograde direction in motor axons. Soc Neurosci Abstr 15:163.

Matthew WD, Greenspan RJ, Lander AD, Reichardt LF (1985) Immunopurification and characterization of a ncuronal heparan sulfate proteoglycan. J Neurosci 5:1842-1850.

Nitkin RM, Smith MA, Magill C, Fallon JR, Yao Y-MM, Wallace BG, McMahan UJ (1987) Identification of agrin, a synaptic organizing protein from Torpedo electric organ. J Cell Biol 105:2471-2478.

Ofosu FA, Buchanan MR, Anvari N, Smith LM, Blajchman MA (1989) Plasma anticoagulant mechanism of heparin, heparan sulfate, and dermatan sulfate. Ann NY Acad Sci 556:123-131.

Pratt CW, Whinna HC, Meade JB, Treanor RE, Church FC (1989) Physicochemical aspects of heparin cofactor IIa. Ann NY Acad Sci 556:104-115.

Reist NE, Magill C, McMahan UJ (1987) Agrin-like molecules at synaptic sites in normal, denervated and damaged skeletal muscles. J Cell Biol 105:2457-2469.

Rogers SL, McCarthy JB, Palm SL, Furcht LT, Letourncau PC (1985) Neuron-specific interactions with two neurite-promoting fragments of fibronectin. J Neurosci 5:369-378.

Role LW, Matossian VR, O'Brien RJ, Fischbach GD (1985) On the mechanism of acetylcholine receptor accumulation at newly formed synapses on chick myotubes. J Neurosci 5:2197-2204.

Skubitz APN, McCarthy JB, Charonis AS, Furcht LT (1988) Localization of three distinct heparin-binding domains of laminin by monoclonal antibodies. J Biol Chem 263:4861-4868.

Suzuki S, Oldberg A, Hayman EG, Pierschbacher MD, Ruoslahti E (1985) Complete amino acid sequence of human vitronectin from cDNA. Similarity of cell attachment sites in vitronectin and fibronectin. EMBO J 4:2519-2524. 
Wallace BG (1986) Aggregating factor from Torpedo electric organ induces patches containing acetylcholine receptors, acetylcholinesterase, and butyrylcholinesterase on cultured myotubes. J Cell Biol 102:783-794.

Wallace BG (1988) Regulation of agrin-induced acetylcholine receptor aggregation by $\mathrm{Ca}^{++}$and phorbol ester. J Cell Biol 107:267-278.

Wallace BG (1989) Agrin-induced specializations contain cytoplasmic, membrane, and extracellular matrix-associated components of the postsynaptic apparatus. J Neurosci 9:1294-1302.
Wallace BG, Nitkin RM, Reist NE, Fallon JR, Moayeri NN, McMahan UJ (1985) Aggregates of acetylcholinesterase induced by acetylcholine receptor-aggregating factor. Nature 31 5:574-577.

Ziskind-Conhaim L, Geffin I, Hall ZW (1984) Redistribution of acetylcholine receptors on developing rat myotubes. J Neurosci 4:23462349 . 